\title{
Early heparin therapy in patients with spontaneous intracerebral haemorrhage
}

\author{
A Boeer, E Voth, Th Henze, H W Prange
}

\begin{abstract}
In 68 patients with spontaneous intracerebral haemorrhage the effect of heparin treatment beginning on the second, fourth or tenth day was investigated. Early (day 2) low-dose heparin medication significantly lowered the incidence of pulmonary embolism. An increase in the number of patients with rebleeding was not observed. The results indicate that the early use of heparin in these patients is safe and can be recommended for the prevention of thromboembolic complications.
\end{abstract}

Patients with spontaneous intracerebral haemorrhage $(\mathrm{ICH})$ are at high risk of venous thromboembolic complications due to the late recognition or asymptomatic course of deepvein thromboses. Thrombus formation is enhanced by immobilisation, pareses of the lower extremities and corticosteroid therapy. Furthermore, the use of diuretic, antihypertensive and sedative agents as well as commonly occurring risk factors pose additional hazards. Moreover, early diagnosis of deepvein thromboses may be delayed due to the lack of subjective complaints from the patients, whose state of consciousness is often impaired. According to some authors, only $30 \%$ of all thrombi are ever recognised. ${ }^{1}$

University Hospital Goettingen,

Goettingen, Germany, Neurological Clinic

A Boeer

Th Henze

$\mathrm{H}$ W Prange

Department of

Nuclear Medicine

E Voth

Correspondence to: $\mathrm{Dr}$ Boeer, Neurological Clinic, University of Goettingen, Robert-Koch-Str 40, 340 Goettingen, Germany

Received 10 April 1990 and in revised form 16 July 1990 in revised form 16 July 1990.

\section{Patients and methods}

In a randomised study ${ }^{2}$ we first investigated the effect of low-dose heparin $(3 \times 5000$ units heparin-sodium/day sc) to reduce pulmonary embolism and deep-vein thrombosis, beginning on the tenth (group 1) or the fourth (group 2) day of treatment. Group 1 patients served as a control group in our intensive care unit as heparin treatment from day 10 was an established part of the treatment protocol for ICH for many years.

Although a higher tendency towards rebleeding did not occur in group 2, there was also no demonstrable reduction in the number

Table 1 Biographical data, pre-existent illness and clinical status

\begin{tabular}{|c|c|c|c|}
\hline & Group $1(n=23)$ & Group $2(n=23)$ & Group $3(n=22)$ \\
\hline $\begin{array}{l}\text { Mean age (yr) } \\
\text { Sex }(\mathrm{f} / \mathrm{m}) \\
\text { Arterial hypertension } \\
\text { Angioma/Aneurysm } \\
\text { Hunt and Hess grade } 2 \\
3 \\
4 \\
5\end{array}$ & $\begin{array}{l}62(46-83) \\
11 / 12 \\
19 \\
5 \\
2 \\
13 \\
6 \\
2\end{array}$ & $\begin{array}{l}60(48-82) \\
12 / 11 \\
18 \\
4 \\
3 \\
13 \\
4 \\
3\end{array}$ & $\begin{array}{l}61(45-83) \\
11 / 11 \\
18 \\
3 \\
1 \\
14 \\
5 \\
2\end{array}$ \\
\hline
\end{tabular}

of deep-vein thromboses and pulmonary emboli. Therefore, an additional group of 22 patients received heparin in the same dose but starting on the second day following the vascular accident. The design of the study accords with the recommendations of the Helsinki Convention of 1975 and was carried out with the approval of the Ethics Committee of the University of Goettingen School of Medicine.

The patients' biographical data as well as their clinical classification according to the HUNT and HESS scale ${ }^{3}$ are shown in table 1. The diagnosis of $\mathrm{ICH}$ was substantiated within 24 hours in all 68 patients using CT. Exclusion criteria were: haemorrhagic diathesis, severe cerebral oedema combined with deep coma (that is, abnormal flexor or extensor responses) and marked arterial hypertension (diastolic value $\geqslant 120 \mathrm{~mm} \mathrm{Hg}$ ). Basic intensive care medication consisted of electrolyte infusions, oral or parenteral nutrition, prophylaxis of peptic ulceration with ranitidine and sucralfate as well as systemic antibiotics. Cerebral oedema was treated with intravenous glycerol $10 \%$ and dexamethasone, the latter starting with $48 \mathrm{mg} /$ day, then tapered slowly thereafter.

The following diagnostic evaluations were carried out in all patients: Cranial CT on days 1, 6 and 10; chest radiograph every two days; phleboscintigraphy of the abdomen and lower limbs on days 2 and 10, in combination with a pulmonary perfusion scintigraphy on the tenth day. Phleboscintigraphy was carried out with in vitro labelled erythrocytes $\left({ }^{99 \mathrm{~m}} \mathrm{Tc} ; 740\right.$ $\mathrm{MBq}) .^{4-6}$ In the pulmonary perfusion scans ${ }^{99 \mathrm{~m}} \mathrm{Tc}$ labelled microspheres were employed (185 MBq).?

Rebleeding was diagnosed, if there was a sudden deterioration of the patient's neurological status and cranial CT performed immediately after showed enlargement of the ICH. A deep-vein thrombosis was diagnosed by venous phleboscintigraphy when segments were missing compared with the contralateral leg. A similar procedure was employed for pulmonary embolism, where missing lobes or segments were ascertained with the chest radiograph as comparison.

Pulmonary embolisms were divided into either symptomatic or asymptomatic events. An embolism was classified to be symptomatic, if there was arterial hypotension or deterioration of pulmonary gas exchange without evidence of sudden cardiac disease, deficiency of circulating blood volume, pneumonia, pneumothorax or septicaemia, 
and pulmonary perfusion scintigraphy revealed embolism.

Statistical analysis was carried out using the Wilcoxon-U test and the Chi-square test with Yates correction.

\section{Results}

Age and sex distribution of the patients as well as predisposing risk factors and the neurological status (HUNT and HESS scale) were evenly divided in the three groups (table 1). There was no overall increase in the incidence of rebleeding. In comparison with the patients in groups 1 and 2 , group 3 patients showed a statistically significant reduction in the number of pulmonary emboli (odds ratio $9,2[1,1-75]$, table 2 ). Three patients in group 1 and one in group 2 had symptomatic pulmonary embolism, whereas in group 3 there was only one embolic event without clinical symptoms. Five patients died in group 2, one as a consequence of a massive pulmonary embolism. Two patients in group 3 , and four in group 1 died. The causes of death were verified at necropsy and consisted of transtentorial herniation, decompensated heart failure and pneumonia. The incidence of deep-vein thrombosis was higher in the first days of treatment (day 2 phleboscintigraphy) than at a later point (phleboscintigraphy day 10 , table 2), where only two additional episodes in group 1 and one episode in group 2 occurred.

\section{Discussion}

The question of early heparin therapy in patients with spontaneous intracerebral haemorrhage is a subject of ongoing controversy. Due to a lack of clinical studies there are no accepted therapeutic guidelines to date. $^{8}$ The fear of rebleeding followed by deterioration of the clinical condition on the one hand, and the danger of thromboembolic complications in those completely immobilised patients on the other, poses a dilemma for the attending physician. Our results show that the danger of thromboembolic complications is very high from the first day on. The occurrence of deep-vein thromboses in patients of all three groups serves to emphasise this fact and correlates well with the experience of other authors. ${ }^{9}$ The incidence of deep-vein thromboses decreased from day two to day 10 , although the difference was not statistically significant. The total number of thromboses in group 1 (43\%) was somewhat lower than results published by some authors. McCarthy et al as well as Czechanowski and Heinrich reported even higher numbers of

Table 2 Complications

\begin{tabular}{llll}
\hline & Group 1 $(n=23)$ & Group 2 $(n=23)$ & Group 3 $(n=22)$ \\
\hline $\begin{array}{l}\text { Deep-vein thrombosis } \\
\quad \text { Day 2) }\end{array}$ & 8 & 7 & 5 \\
New deep-vein thrombosis & 2 & 1 & 0 \\
$\quad$ Day 10) & 5 & 1 & 1 \\
Pulmonary embolism & 9 & 14 & 0 \\
Symptomatic embolism & 3 & 1 & 16 \\
No evidence of thrombosis & 11 & 5 & 0 \\
$\quad$ or pulmonary embolism & 3 & 2 \\
Rebleeding & 4 & & \\
Death & & &
\end{tabular}

deep-vein thromboses in stroke patients reaching an incidence of 56-75\%. ${ }^{910}$

The results of our study show that early low-dose subcutaneous heparin treatment does not necessarily lead to an increased incidence of rebleedings. This is in contrast to another group of cardiovascular diseases, cardioembolic brain infarctions, which are often followed by haemorrhagic transformation, regardless of whether anticoagulation is performed. ${ }^{11}{ }^{12}$ In these cases, spontaneous revascularisation of the occluded vessel often occurs, which is followed by the reflow of blood into the damaged brain tissue and thus causes haemorrhagic transformation. In contrast, the vascular source of primary $\mathrm{ICH}$ is surrounded by an area of increased tissue pressure, which may satisfactorily prevent rebleeding. Factors which could contribute to an increasing risk of rebleeding, such as uncontrolled arterial hypertension or a prolonged bleeding time due to an overdose of heparin, must be strictly avoided.

Early low-dose heparin therapy in patients with ICH seems to be as safe as in the postoperative care for gynaecology and orthopaedics and the surgical procedures, where the incidence of haemorrhagic complications, especially wound haematomas, ranges from $0 \%$ to $9 \% .{ }^{1314}$

In conclusion, patients with intracerebral haemorrhage are at high risk of developing thromboses due to corticosteroid therapy and prolonged immobilisation. In our study, lowdose heparin therapy beginning on the second day of treatment significantly reduced the number of pulmonary emboli when compared with heparin treatment beginning on the fourth or tenth day, without increasing the risk of rebleeding. The use of heparin therefore on the second day following intracerebral haemorrhage is apparently not dangerous and can be further recommended.

1 Alpert JS, Smith R, Carlson IS, Dexter L, Dalen JE. Mortality in patients treated for pulmonary embolism. Mortality in patients treated for
$J$ Am Med Ass 1976;236:1466-80.

2 Dickmann U, Voth E, Schicha H, Henze Th, Prange $H$, Emrich D. Heparin therapy, deep-vein thrombosis and pulmonary embolism. Klin Wochenschr 1988;66:1182-3.

3 Hunt WE, Hess RM. Surgical risk as related to time of intervention in the repair of intracranial aneurysms. $J$ Neurosurg 1968;28:14-20.

4 Beswick W, Chmiel R, Booth R, Vellar J, Gilford E, Chesterman $C N$. Detection of deep vein thrombosis by scanning of ${ }^{99 m}$ Technetium labeled red-cell venous pool. $B M J 1979 ; \mathrm{i}: 82-4$.

5 Lisbona R, Stern J, Derbekyen V. ${ }^{99 m}$ Tc red blood cell venography in deep vein thrombosis of the leg: a correlation with contrast venography. Radiology 1982;143:771-3.

6 Neumann P, Schicha H, Schürnbrand P, Bähre M, Emrich $D$. Visualizing cardiac blood pool: comparison of three labeling methods. Eur J Nucl Med 1983;8:463-66.

7 Emrich D. Nuklearmedizinische diagnostik und therapie. Stuttgart: Thieme, 1976:98-102.

8 Magee KR. Intracerebral hemorrhage. In: HF Conn, ed. Current therapy. Philadelphia: Saunders, 1982:710-12.

9 Czechanowski B, Heinrich F. Prophylaxe venöser Thrombosen bei frischen ischämischen cerebrovaskulären Insulbosen bei frischen ischämischen cerebrovask
ten. Dt Med Wochenschr 1981;106:1254-60.

10 McCarthy ST, Turner JJ, Robertson D, Hawkey CJ, Macey DJ. Low-dose-heparin as a prophylaxis against deep vein thrombosis after acute stroke. Lancet 1977;ii:800-1.

11 Ott BR, Zamani A, Kleefield J, Funkenstein HH. The clinical spectrum of hemorrhagic infarction. Stroke 1986;17:630-7.

12 Cerebral Embolism Study Group. Cardioembolic stroke, early anticoagulation, and brain haemorrhage. Arch Intern Med 1987;147:636-40.

13 Bergquist $D$. Prophylaxis of postoperative thromboembolic complications with low-dose heparin. Acta Chir Scand 1979;145:7-11.

14 Seglias J, Gruber UF. Dosage in low-dose heparin prophylaxis. Haemostasis 1979;8:361-4. 